\title{
Flows' Similarities between Tornadoes or Cyclones Kinematics and Motions Resulting from Weather Phenomena Coupling Geostrophic Wind with Passive Convection
}

\author{
César Mbane Biouele \\ Laboratory of Earth's Atmosphere Physics, Department of Physics, University of Yaoundé I, Yaoundé, \\ Cameroun \\ Email: cesar.mbane@yahoo.fr
}

Received 16 March 2016; accepted 19 June 2016; published 22 June 2016

Copyright (C 2016 by author and Scientific Research Publishing Inc.

This work is licensed under the Creative Commons Attribution International License (CC BY). http://creativecommons.org/licenses/by/4.0/

c) (i) Open Access

\section{Abstract}

Tornadoes and cyclones, as is stated in numerous literary and audiovisual works dedicated to these out of balance physical systems, are two powerful and spectacular atmospheric phenomena whose vertical and horizontal profiles of winds and temperatures are not yet well known. Indeed, data and routine observations accumulated in the World Meteorological Organization (WMO) databases, regardless of their diversity and perfection of the instruments used to achieve these data (e.g. satellites, onboard cameras, wind profilers, ultra modern calculators, etc.), offer mind-blowing performances on the extent of damage caused by these disturbances, but information provided by these ground and space based observations will never allow access to real profiles of winds associated with tornadoes and cyclones both at the ground's surface and aloft. The works recently carried out by $C$. Mbane Biouele allow us to discover that winds associated with tornadoes and hurricanes result from vectors addition of troposphere's horizontal geostrophic winds and vertical movements associated with passive convection. Unfortunately, geostrophic wind and passive convection are two familiar meteorological phenomena described with much awkwardness and monumental mistakes by all scientific books written by authors who have remained loyal to Hadley principle which states (for centuries) that hot air is lighter than cold air. It is very important to know that C. Mbane Biouele's very recent publications demonstrate that Hadley principle is not valid in the troposphere's regions occupied by Ferrell cells. Indeed, it is urgent for the development of meteorology to highlight with great insistence to everyone that there is a Physics principle diametrically opposed to popular Hadley one which provides thermodynamic reasons of the formation of Ferrell cells. This Principle will be named Mbane Biouele Principe and be clearly stated 
in this paper.

Keywords

Flows' Similarities, Tornadoes' or Cyclones' Kinematics, Georges Hadley and Mbane Biouele Principles, Troposphere's Passive Convection Flows and Geostrophic Winds

\section{Introduction}

Scientists interested in weather climate make extensive use of both George Hadley Principle (stated in 1735) and closely related to specifics on ideal gas) and geostrophic winds' behavior in their practices to explain many meteorological phenomena such as the direction of the winds that take place around low pressure systems such as Tornadoes and Cyclones. The questioning that faces the public interested in information disseminated by meteorologists is to know exactly which Troposphere's areas can be considered as ideal gas (that means opened to G. Hadley Principle) and what is the truly meaning of geostrophic wind. Besides the wholly misconceived descriptions of both troposphere's passive convection and geostrophic winds scattered in many scientific works, there is unfortunately no book which gives importance to the mathematical modelling of these two familiar phenomena. E.g., according to most observers, the reason why the geostrophic wind is parallel (instead of near parallel) to the isobars is (until now) not well explained by a relevant theory. Teaching those who study the earth's atmosphere physics that the geostrophic wind leaves depressions on the left in the northern hemisphere (or on the right in the southern hemisphere) without providing any mathematical formula that consolidates these very useful principles, is the same think as preaching in the desert. In this paper, efforts will be made so that many well-known principles on passive convection and geostrophic motions set without proper mathematical formula will be explained, as simple as possible, accordingly to these principles' related algebraic formulas. Our Mathematical approach has the biggest advantage of highlighting all the relevant characteristics of geostrophic wind (e.g., geostrophic wind's characteristics already known to the public and its specifics completely unknown even by specialists in meteorology) and passive convection flows throughout all Troposphere's floors. In this paper, we also want to show that due to very strong surface winds that accompany them, tornadoes and cyclones occur in a lying on the ground's surface deep column in which the geostrophic balance settles. Undoubtedly, interpretations of Tornadoes or Cyclones Thermodynamics and Dynamics will next be an easy exercise to researchers who will give importance to results on Troposphere's deep and passive convection or geostrophic balance motions revealed in this paper.

\section{Troposphere's Passive Convection Flows According to Mbane Biouele Principle}

When G. Hadley develop his Principle (1735) which states that: "hot air is lighter than cold air", he didn't know the existence of Ferrell Cells and also the thermodynamic reasons for the formation of these Ferrell cells. Unfortunately, many researchers who are not (so far) informed of the results obtained by C. Mbane Biouele results which highlight the thermodynamic reasons for the formation of Ferrell cells and clearly specify the geographical location of this famous cells [1]-[5], continue to blindly apply the G. Hadley principle including in Troposphere's areas where this principle is completely wrong. It is therefore urgent for the development of meteorology to highlight with great insistence to everyone that there is a Physics principle diametrically opposed to the popular Hadley one, which in the future will be named Mbane Biouele Principe and thereafter be stated: "In those areas of the Earth's atmosphere located (Figure 1) between $0.0098^{\circ} \mathrm{C}$ isotherm and $6.11 \mathrm{mb}$ equal vapor surface, warm parcels of moister air are heavier than cold parcels of moister air”.

\subsection{Application of Mbane Biouele Principle to Earth's Atmosphere General Circulation}

Meridian Cells of the General Circulation, views under the new perspectives open by Mbane Biouele principle [1]-[5] logically occupy the three (03) hemispheric areas clearly described in Figure 1. This relevant approach allows a much more realistic configuration (Figure 2) of daily mean flows associated with earth's atmosphere general circulation. 


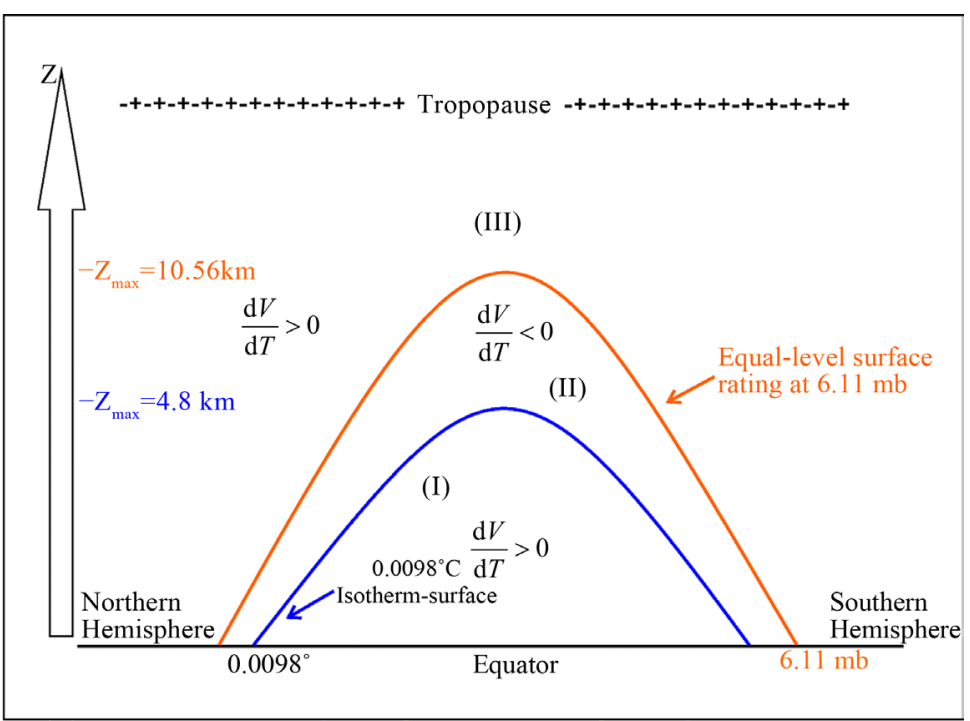

Figure 1. "Hot air is lighter than cold air" in regions (I) and (III) where: $\frac{\mathrm{d} V}{\mathrm{~d} T}>0$. Conversely "Cold air is lighter than hot air” in regions (II) where: $\frac{\mathrm{d} V}{\mathrm{~d} T}<0 . V$ and $T$ represent respectively the air parcel's volume and temperature.

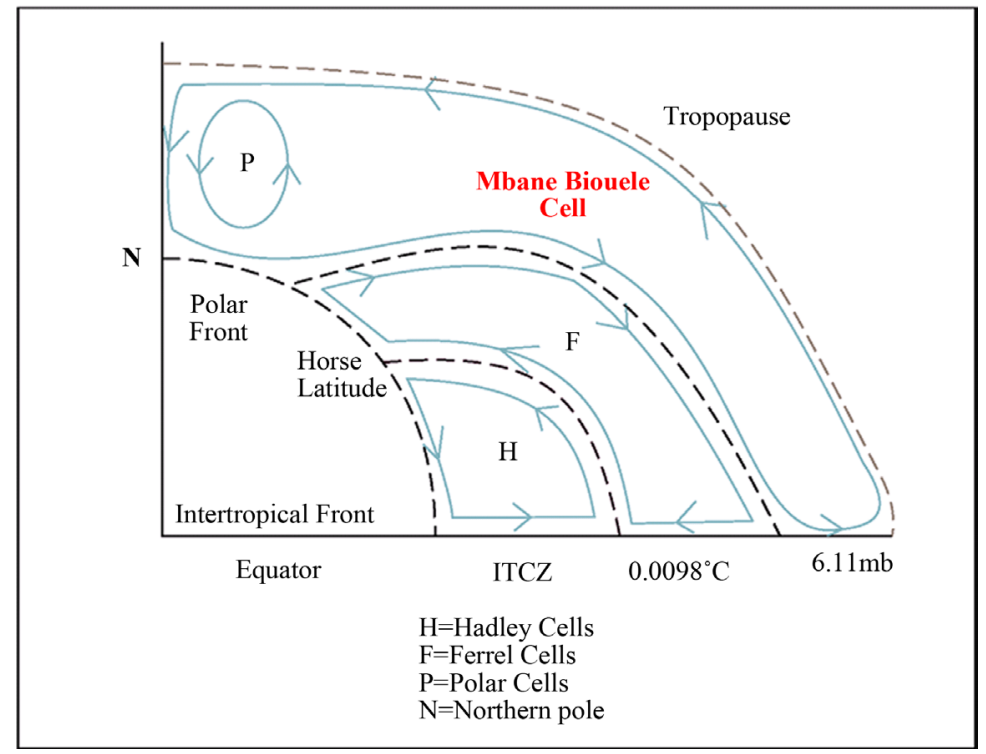

Figure 2. Earth's atmosphere general circulation according to MBANE BIOUELE principle [1]. The biggest cell that stretches from Northern pole to ITCZ is named "Mbane Biouele Cell" by the author (Cesar MBANE BIOUELE in this case) who has proven its existence.

\subsection{Application of Mbane Biouele Principle to Troposphere's Deepest Passive Convection}

Figure 3 and Figure 4 describe the flows associated respectively to troposphere's cold and hot deepest passive convection. Clouds and electrical charges and fields resulting from that flows are also shown.

\section{Geostrophic Winds Horizontal Profiles}

\subsection{Equation of Relative Motion in Rectangular Coordinates}

The equation of relative motion in rectangular coordinates is 


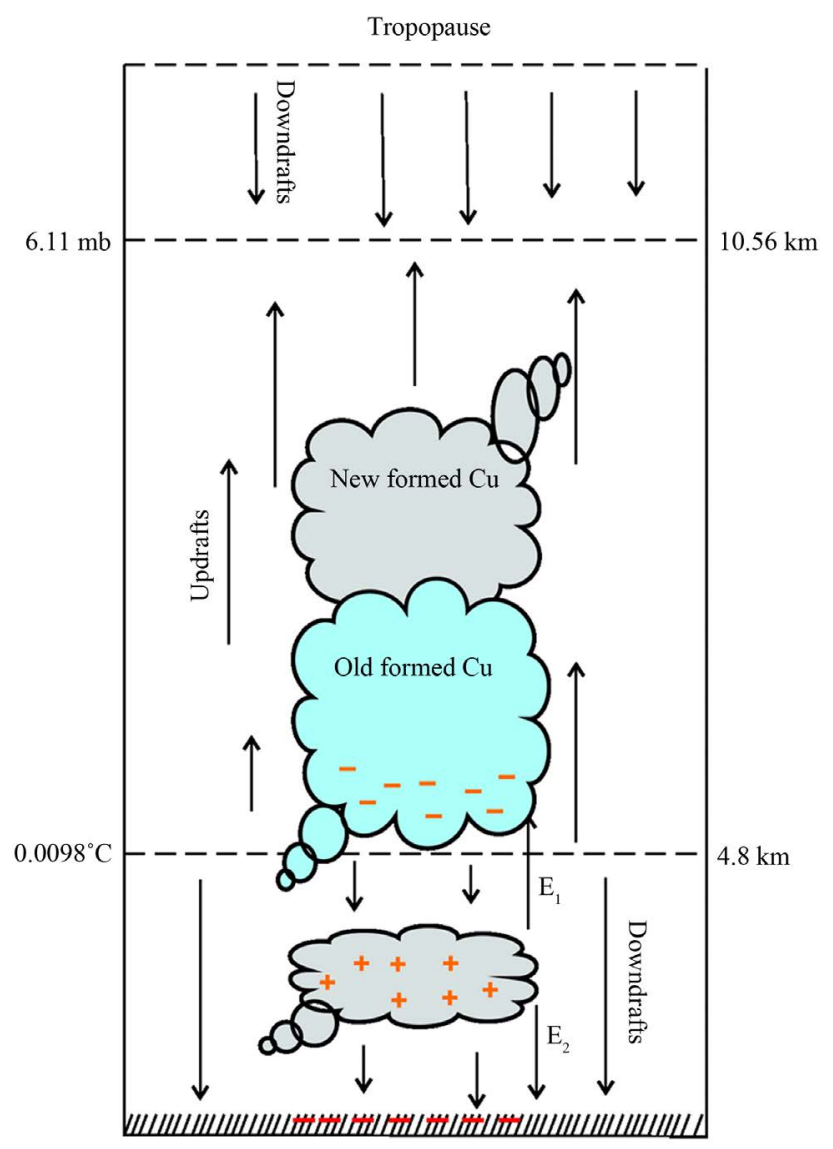

Figure 3. Vertical profiles in both 03 floors of cold and deepest passive convection flows.

$$
\frac{\mathrm{d} \boldsymbol{V}}{\mathrm{d} t}=-\frac{1}{\rho} \nabla p-2 \boldsymbol{\Omega} \Lambda \boldsymbol{V}+\boldsymbol{g}+\Pi .
$$

The symbol $\boldsymbol{V}$ denotes the relative velocity, i.e., the velocity relative to a point which is fixed with respect to the surface of the earth. The accelerations and forces are (all per unit mass):

$\frac{\mathrm{d} \boldsymbol{V}}{\mathrm{d} t}=$ relative acceleration,

$\frac{1}{\rho} \nabla p=$ pressure gradient force,

$-2 \Omega \Lambda \boldsymbol{V}=$ Coriolis force,

$\boldsymbol{g}=$ force of gravity,

$\Pi=$ "frictional" force.

Meteorologists have at least an intuitive feeling that fluid flow is somehow related to the mass distribution of the fluid. However, there is no equation in all of fluid dynamics which would allow us to infer the velocity field given knowledge of the mass field. All we can infer are time-rates-of-change of the velocity field, i.e., accelerations. We have already seen [1]-[5] that molecular frictional forces can be neglected for most purposes in the free atmosphere. The question now arises: are there situations where some of the remaining forces in the equation of motion are negligible? The answer to this question is "yes", and we shall now discuss one very important case: the geostrophic wind (or geostrophic balance).

\subsection{The Geostrophic Balance Equation}

The situation where some of the remaining forces of Equation (1) are negligible can be described by (Equation 2) 


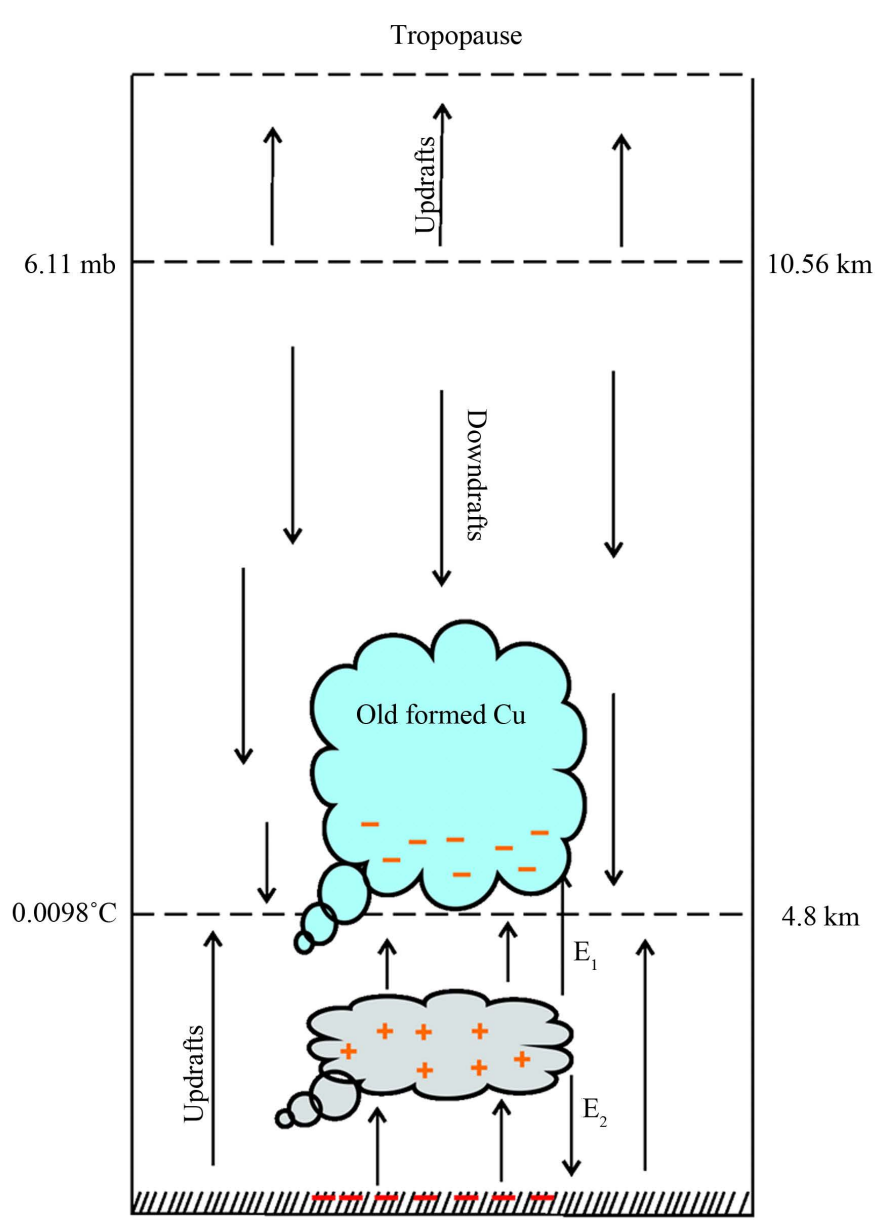

Figure 4. Vertical profiles in both 03 floors of hot and deepest passive convection flows.

called the geostrophic balance equation

$$
\frac{1}{\rho} \nabla p-2 \Omega \Lambda \boldsymbol{V}+\boldsymbol{g}=\mathbf{0} .
$$

In which relative acceleration and frictional force are negligible compared to pressure, Coriolis and gravitation force.

\subsection{The Geostrophic Wind in Rectangular Coordinates}

Using vector product (symbol $\Lambda$ ), we can transform Equation (2) and write (2-a)

$$
\boldsymbol{k} \Lambda\left(-\frac{1}{\rho} \nabla p-2 \boldsymbol{\Omega} \Lambda \boldsymbol{V}+\boldsymbol{g}\right)=\boldsymbol{k} \Lambda \mathbf{0}=\mathbf{0} .
$$

In the goal to obtain (2-b)

$$
2 \Omega(\boldsymbol{k} \cdot \boldsymbol{K}) \boldsymbol{V}-2 \Omega(\boldsymbol{k} \cdot \boldsymbol{V}) \boldsymbol{K}-\frac{1}{\rho} \boldsymbol{k} \Lambda \nabla p=\mathbf{0}
$$

where: $\boldsymbol{k} \Lambda \Delta p$ is perpendicular to the horizontal pressure gradient vector, $\boldsymbol{K}$ is $\boldsymbol{\Omega}$ unit vector, and $\boldsymbol{k} \cdot \boldsymbol{V}=\mathbf{0}$ in the case of the phenomenological definition of geostrophic wind.

Hence:

The Geostrophic Vector (or Wind) in the Northern-Hemisphere 


$$
\boldsymbol{V}_{\text {geostrophic }}=\frac{1}{2 \rho \Omega \sin \phi} \boldsymbol{k} \Lambda \nabla p .
$$

The Geostrophic Vector (or Wind) in the Southern-Hemisphere

$$
\boldsymbol{V}_{\text {geostrophic }}=-\frac{1}{2 \rho \Omega \sin \phi} \boldsymbol{k} \Lambda \nabla p \text {. }
$$

N.B.: The Geostrophic Vector (or wind) in the Southern Hemisphere is of opposite sign to the Geostrophic Vector (or wind) in the Northern Hemisphere.

\subsection{Fundamentals of Geostrophic Wind Dynamics and Thermodynamics}

Equations (3) and (4) lead to 06 geostrophic vector specifics (or fundamental properties):

$\mathbf{P}_{1} /$ the geostrophic winds (as defined) are perpendicular to the horizontal pressure gradient vector:

$\boldsymbol{k} \Lambda \nabla p=\boldsymbol{k} \Lambda \nabla_{H} p$ where $\nabla_{H} p$ is horizontal pressure gradient vector.

$\mathbf{P}_{\mathbf{2}}$ /the geostrophic winds (as defined) are horizontal (they are perpendicular to $\boldsymbol{k}$ ).

$\mathbf{P}_{3} /$ the geostrophic wind (as defined) is parallel (or tangent at any point) to the isobars.

Proof: along an isobar, $\nabla p$ is perpendicular to the elementary displacement $\mathrm{d} \boldsymbol{M}$. The mathematical reason is the fact that, along an isobar, $\mathrm{p}$ is a Constant. Therefore

$$
\mathrm{d} p=\frac{\partial p}{\partial x} \mathrm{~d} x+\frac{\partial p}{\partial y} \mathrm{~d} y=\nabla p \cdot \mathrm{d} \boldsymbol{M}=0
$$

This allows stating $\mathbf{P}_{3}$.

$\mathbf{P}_{4}$ /the geostrophic winds (as defined) are inversely proportional to $\sin \phi$. Its magnitude is therefore able to dizzily increase close to the equator (where $\sin \phi$ tends to zero): Geostrophic winds are (as defined) more devastating in the tropics than in temperate or Polar Regions.

$\mathbf{P}_{5} /$ The geostrophic winds are (as defined) stronger when the density $(\rho)$ of air decreases.

$\mathbf{P}_{6} /$ the geostrophic winds (as defined) move leaving the low pressure to their left in the Northern Hemisphere. They move leaving the low pressure to their right in the Southern Hemisphere (Figure 5).

(This statement is provided by the properties of the vector product).

\section{Helicoidally Flows Associated with Tornadoes and Cyclones}

Profiles of flows associated with Tornadoes and Cyclones depend mainly to the tropospheric floor and the Hemisphere (North or South) in which those fluid flows are observed. Indeed, tornadoes' and cyclones' result from geostrophic winds (parallel to horizontal isobars) coupled with troposphere's deep and passive convection flows (Figure 6 and Figure 7).

N.B.: Tornadoes' and Cyclones' winds did not have radial component (regardless to air particles' trajectories) as often stated.

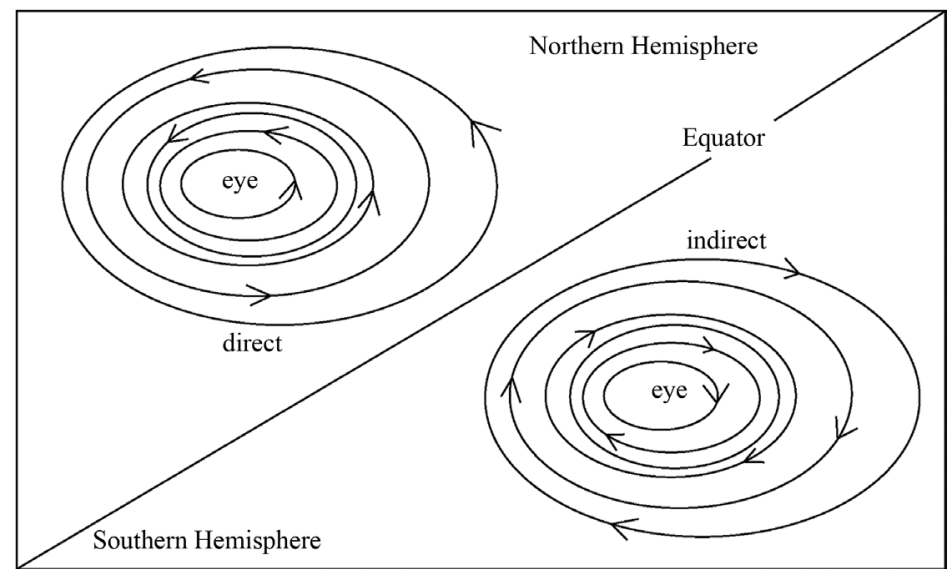

Figure 5. Low pressure kinematics in Northern and Southern Hemispheres [1]. 


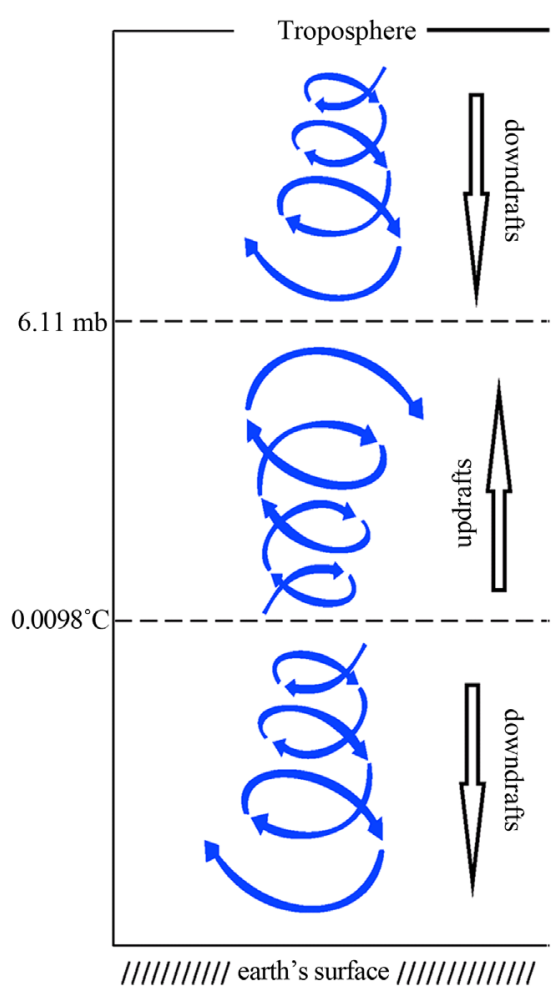

Figure 6. Helicoidally flows associated to Cyclones (or cold low pressure systems) in the Southern Hemisphere [1].

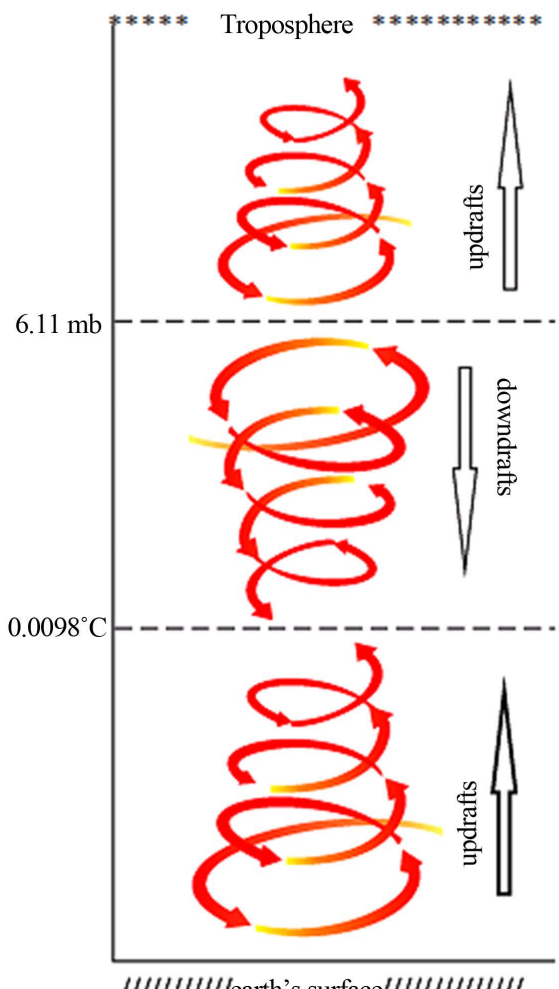

Figure 7. Helicoidally flow associated to Tornadoes (or hot low pressure systems) in the Northern Hemisphere [1]. 


\section{Conclusion}

Results proposed in this paper will provide a better understanding of atmospheric phenomena, regardless of their complexity. George Hadley Principle, famous at the century of its development (1735), needed to be improving accordingly to too many contradictions that modern observing tools opposed to it such as kinematics of Ferrel cells discovered in 1860, long after G. Hadley principle. We hope that in the near future, all necessary corrections on the interpretations of meteorological phenomena (mainly interpretations inspired by the G. Hadley principle) will be made wisely. So that meteorology being modernized and that all myths that accompany many climate phenomena disappear forever. Tornadoes (for example) should no longer be regarded as inevitable.

\section{References}

[1] Mbane Biouele, C. (2015) Earth’s Atmosphere Dynamic Balance Meteorology. Scientific Research Publishing Inc., USA, $110 \mathrm{p}$.

[2] Mbane Biouele, C. (2015) Fundamentals on Thermodynamic Processes behind Cloud's and Rainfall's Formation. Atmospheric and Climate Sciences, 5, 257-265. http://dx.doi.org/10.4236/acs.2015.53019

[3] Mbane Biouele, C. (2015) Relationship between Disruptions of Carbon's Cyclic Set Natural Transfers and the Upsurge of Weather Conditions with Strong Winds and Heavy Rains. Atmospheric and Climate Sciences, 5, 380-385. http://dx.doi.org/10.4236/acs.2015.54029

[4] Mbane Biouele, C. (2015) Useful and Unique Descriptions of Tropospheric Process Which Produce Oxygen and Thereafter Give Birth to Equatorial Electro-Jets. International Journal of Geosciences, 6, 1248-1253. http://dx.doi.org/10.4236/ijg.2015.611098

[5] Nkoa Nkomom, T., Mbane Biouele, C. and Mane Mane, J. (2016) Numerical Simulation of Water Wave’s Modulational Instability under the Effects of Wind's Stress and Gravity Force Relaxation. OJMS, 6, 93-102. http://dx.doi.org/10.4236/ojms.2016.61009

\section{Submit or recommend next manuscript to SCIRP and we will provide best service for you:}

Accepting pre-submission inquiries through Email, Facebook, Linkedin, Twitter, etc

A wide selection of journals (inclusive of 9 subjects, more than 200 journals)

Providing a 24-hour high-quality service

User-friendly online submission system

Fair and swift peer-review system

Efficient typesetting and proofreading procedure

Display of the result of downloads and visits, as well as the number of cited articles

Maximum dissemination of your research work

Submit your manuscript at: http://papersubmission.scirp.org/ 